\title{
The soluble CTLA-4 receptor and its role in autoimmune diseases: an update
}

\author{
Daniele Saverino • Rita Simone • Marcello Bagnasco • \\ Giampaola Pesce
}

Received: 7 September 2010 / Accepted: 8 September 2010

(C) Springer-Verlag 2010

\begin{abstract}
CTLA-4, initially described as a membranebound molecule, is a costimulatory receptor transducing a potent inhibitory signal. Increasing evidence shows the CTLA-4 gene to be an important susceptibility locus for autoimmune endocrinopathies and other autoimmune disorders. A soluble form of cytotoxic T-lymphocyte-associated antigen-4 (sCTLA-4) has been established and shown to possess CD80/CD86 binding activity and in vitro immunoregulatory functions. sCTLA-4 is generated by alternatively spliced mRNA. Whereas low levels of SCTLA-4 are detected in normal human serum, increased serum levels are observed in several autoimmune diseases (e.g. Graves' disease, myasthenia gravis, systemic lupus erythematosus, type 1 diabetes, systemic sclerosis, coeliac disease, autoimmune pancreatitis and primary biliary cirrhosis). The biological significance of increased sCTLA-4 serum levels is not fully clarified yet. On the one hand, it can be envisaged that sCTLA-4 specifically inhibits early T-cell activation by blocking the interaction of CD80/CD86 with the costimulatory receptor CD28. On
\end{abstract}

D. Saverino $\cdot$ R. Simone

Section of Human Anatomy,

Department of Experimental Medicine,

University of Genova, Italy

M. Bagnasco $(\varangle) \cdot$ G. Pesce

Medical and Radiometabolic Therapy Unit,

Department of Internal Medicine,

University of Genova,

Viale Benedetto XV, 6,

16132 Genova, Italy

Tel.: +39-010-3537979

E-mail: bagnasco@unige.it the other hand, higher levels of sCTLA-4 could compete for the binding of the membrane form of CTLA-4 with CD80/CD86 in the later phases of T-lymphocyte activation, causing a reduction in inhibitory signalling. This double-edged nature of sCTLA-4 to block the binding of CD28 to CD80/CD86 may result in different outcomes during the clinical course of an autoimmune disease.

Keywords CTLA-4 · Immunoregulation · Autoimmune disease $\cdot$ T-cell activation

\section{Introduction}

The antigen-specific T-lymphocytes response is a result of two signals: the first needs T-cell receptor (TCR)/CD3 recognition of an antigen/major histocompatibility complex molecule expressed on antigen-presenting cells (APCs), and the second (also called the costimulatory signal) is typically mediated by the interaction of CD28 with B7 family members on APCs [1]. Triggering TCR/CD3 alone in the absence of a costimulatory signals not only fails to induce an immune response, but can also lead to a state of hyporesponsiveness or anergy [2]. Among B7 ligands, CD28 is the major costimulatory molecule constitutively expressed on the majority of $\mathrm{T}$ cells [3]. In contrast, cytotoxic T-lymphocyte antigen-4 (CTLA-4, CD152), a homologue to CD28, is a T-cell costimulatory receptor able to attenuate the immune response [4-6]. CTLA-4 is expressed on activated T cells (both $\mathrm{CD}^{+}$and $\mathrm{CD}^{+}$) and $\mathrm{B}$ cells [7] and on monocytes and dendritic cells [8], and acts to downregulate cell functions. In addition, CTLA-4 is expressed on the surface of regulatory $\mathrm{T}$ cells, acting largely as a negative regulator of $\mathrm{T}$ cell responses [9]. Because of its inhibito- 
ry functions, CTLA-4 could cause a breakdown of immunological self-tolerance influencing the development of (or the susceptibility to) autoimmunity.

A native soluble form of CTLA-4 (sCTLA-4) has been described [10]. The presence of high serum concentrations of sCTLA-4 is correlated with several autoimmune diseases [11]. Moreover, increased plasma levels of sCTLA-4 have been observed in patients with allergic asthma [12] and allergy to Hymenoptera venom, but not in those with allergic rhinitis [13]. A very recent study has indicated the possibility of using SCTLA-4 as a biomarker of inflammation [14].

We present an up to date review of the possible relationships between sCTLA-4 and autoimmune disorders. The literature data from the last few years provides increasing evidence for the involvement of CTLA-4, and also for the presence of circulating functional SCTLA-4, in autoimmune diseases. On the other hand, the relationship between the ability to produce SCTLA-4 and the genetic regulation/modification of CTLA-4 is the not yet fully clarified, and in some aspects is contradictory.

\section{Autoimmunity and CTLA-4 genetics}

Autoimmune diseases tend to cluster within families and it is not uncommon that patients are diagnosed with more than one autoimmune disease. Otherwise, inheritance of autoimmune disorders is in general very complex and most likely due to the presence of multiple susceptibility genes, and to modulating environmental factors.

Candidate gene association studies have been performed to identify genetic variants predisposing to several autoimmune diseases. However, the role of most of these candidate susceptibility genes remains controversial. The ability of CTLA-4 to regulate T and B cells has been extensively explored in various human autoimmune diseases, and the results suggest a relevant role in autoimmunity. Originally, an association between CTLA4 and autoimmune disease was demonstrated in a casecontrol study involving patients with Graves' disease (GD) [15]. Subsequently, the three known polymorphisms of the CTLA-4 gene were investigated for linkage and/or association in a large number of human autoimmune diseases. Of interest, some polymorphisms of the gene, such as those of exon 1 which alter CTLA-4 transcription, increase susceptibility to type 1 diabetes (T1D) and other autoimmune diseases [16-19].

The human CTLA-4 gene consists of four exons: exon 1 encodes a leader peptide (of approximately 37 amino acids), exon 2 the ligand-binding domain (116 amino acids), exon 3 the transmembrane domain (37 amino acids), and exon 4 the cytoplasmic tail (34 amino acids) [20-23].
The human CTLA-4 gene is known to contain several polymorphisms. The following three CTLA-4 polymorphisms have been the most frequently studied in several autoimmune diseases. The first identified was the dinucleotide (AT)n repeat polymorphisms located in the $3^{\prime}$ untranslated region (3'-UTR) of exon 4 at position 642 (Genbank no. M37243, locus HUMIGCTL3) [24]. The second polymorphism reported was a transition at position $49(\mathrm{~A} / \mathrm{G})$ of exon 1 which leads to substitution of threonine to alanine in codon 17 of the leader peptide (Genbank no. M74363) [25]. The third polymorphism is characterized by a $\mathrm{C}$ to $\mathrm{T}$ transition at position -319 (C$319 \mathrm{~T}$ ) of the promoter region (Genbank no. M74363) [16]. In recent years, a number of other CTLA-4 polymorphisms within the CTLA-4 gene have been discovered and analysed (for review see reference [11]).

\section{Autoimmune thyroid diseases}

Autoimmune thyroid diseases (AITD) are the most common human autoimmune disorders, affecting more than $5 \%$ of the general population [26]. AITD include two related disorders: GD and the more common Hashimoto's thyroiditis (HT). GD and HT have very different clinical phenotypes, the former resulting, as a rule, in thyroid hyperfunction due to thyroid-stimulating TSH receptor antibodies, the latter in follicular cell damage (mainly cell-mediated), but share common immunogenetic factors [27]. Linkage of HLA susceptibility genes with AITD have only been confirmed in some ethnic groups suggesting that the HLA locus has only a minor influence on the overall genetic predisposition [28].

The CTLA4 locus is the only non-HLA locus for which the association with GD has been repeatedly demonstrated since 1995, when the first evidence for an association with the CTLA-4 3'-UTR-microsatellite in a Caucasian population was reported [29]. Linkage and association of the $C T L A-4$ exon 1 polymorphism with GD, and to lesser extent with HT, has been found in several populations, although there seems to be some inconsistency, probably due to population heterogeneity [11, 17, 27, 30-33] (Table 1).

\section{Type 1 diabetes}

T1D (or insulin-dependent diabetes mellitus) is genetically complex and is characterized by immune-mediated selective destruction of the pancreatic insulin-secreting cells. T1D may develop throughout life, but peaks in childhood. T1D was the first multifactorial disease to be investigated by the whole genome linkage analysis 
Table 1 Genetic studies of CTLA-4 polymorphisms in autoimmune diseases

\begin{tabular}{|c|c|c|c|c|c|c|}
\hline Disease & No. of patients & No. of controls & Population & Polymorphism & $p$ value & Reference \\
\hline \multirow[t]{14}{*}{ GD } & 2,640 & 2,204 & Chinese Han & & & 30 \\
\hline & & & Combined & rs231779 & $2.81 \times 10^{-9}$ & \\
\hline & & & & rs35219727 & 0.9792 & \\
\hline & & & Shandong & rs231779 & 0.0019 & \\
\hline & & & & rs35219727 & $1.3 \times 10^{-5}$ & \\
\hline & & & Xuzhou & rs231779 & $1.37 \times 10^{-5}$ & \\
\hline & & & & rs35219727 & 0.5995 & \\
\hline & & & Southern & rs 231779 & 0.0071 & \\
\hline & & & & rs35219727 & 0.0961 & \\
\hline & 436 & 316 & Chinese & rs231779 & 0.017 & 31 \\
\hline & 200 & 118 & US & $+49 \mathrm{~A} / \mathrm{G}$ & 0.018 & 32 \\
\hline & 99 & 93 & Polish & $+49 \mathrm{~A} / \mathrm{G}$ & 0.55 & 33 \\
\hline & & & & СТ60 & 0.03 & \\
\hline & & & & Jo31 & 0.02 & \\
\hline \multirow[t]{2}{*}{ HT } & 63 & 231 & Slovak/Slovene & $+49 \mathrm{~A} / \mathrm{G}$ & $<0.05$ & 34 \\
\hline & & & & СТ60 & $<0.0005$ & \\
\hline \multirow[t]{5}{*}{ T1D } & 320 & 231 & Slovak/Slovene & $+49 \mathrm{~A} / \mathrm{G}$ & $<0.05$ & 34 \\
\hline & & & & СT60 & $<0.0005$ & \\
\hline & 61 & 230 & Estonian & СТ60 & 0.004 & 35 \\
\hline & 396 & 396 & Egyptian & $+49 \mathrm{~A} / \mathrm{G}$ & 0.000575 & 36 \\
\hline & & & & C-819T & 0.0047 & \\
\hline MG & 46 & 98 & Venezuelan & $+49 \mathrm{~A} / \mathrm{G}$ & 0.002 & 39 \\
\hline MS & 198 & 224 & Australian & $+49 \mathrm{~A} / \mathrm{G}$ & n.s & 40 \\
\hline AR & 199 & 199 & Mexican & $+49 \mathrm{~A} / \mathrm{G}$ & 0.1 & 41 \\
\hline \multirow[t]{2}{*}{$\mathrm{CD}$} & 120 & 231 & Slovak/Slovene & $+49 \mathrm{~A} / \mathrm{G}$ & n.s. & 34 \\
\hline & & & & СТ60 & n.s. & \\
\hline PBC & 308 & 268 & Japanese & Haplotype 1 & 0.0095 & 48 \\
\hline
\end{tabular}

n.s. not significant

approach [11, 34, 35], and several non-HLA T1D susceptibility loci (IDDM2-17) have revealed some evidence of linkage with the disease. CTLA-4 is considered from a functional point of view, and on the basis of mapping studies, the most likely known candidate gene. The first evidence dates back 15 years, when for the first time linkage to the CTLA-4 region in an Italian T1D dataset was reported [24]. Furthermore, several family datasets from Italy, Sardinia, Spain, the UK and the US were analysed for association with the CTLA-4 exon 1 polymorphism. Even though a positive association was found only in the Italian and Spanish data, combining all five datasets provided significant evidence of an association between the A49G allele and T1D. There have been several subsequent studies and, despite some inconsistencies, in most of these studies CTLA-4 polymorphisms were found to be associated with T1D [34-36] (Table 1).

\section{Myasthenia gravis}

The autoimmune process in myasthenia gravis (MG) causes a postsynaptic blockade of neuromuscular conduction mediated by autoantibodies directed against the acetylcholine receptor $[37,38]$. Candidate genes for $\mathrm{MG}$ include the HLA, immunoglobulin genes, T-cell antigen receptor genes and the acetylcholine receptor gene [11]. In addition, the association between CTLA-4 polymorphisms and MG has been investigated. Results obtained very recently in one group of MG patients showed that the +49A/G genotype is moderately increased in MG and pemphigus [39] (Table 1).

\section{Multiple sclerosis}

Multiple sclerosis (MS) is a chronic demyelinating disease that affects the central nervous system. The cause of MS is unknown, but it has been proposed that the myelin damage is immune-mediated (perivascular mononuclear cell infiltrates precede myelin loss), either secondary to a viral infection or a direct autoimmune process. The association between HLA and MS is well documented, while linkage of the CTLA4 region remains uncertain $[11,40]$ (Table 1).

\section{Rheumatoid arthritis}

Rheumatoid arthritis (RA) is a chronic inflammatory polyarthritis of unknown aetiology characterized by remark- 
able hyperplasia of synovial lining cells, neovascularization, and intense infiltration in the synovium of mononuclear cells, predominantly $\mathrm{CD}^{+}{ }^{+} \mathrm{T}$ cells $[11]$. These features, together with the presence of rheumatoid factor and/or anticitrullinated cyclic peptide antibodies, indicate that RA is an autoimmune disease. Again, the occurrence of RA is strongly associated with the expression of specific HLA-class II alleles [11], whereas linkage to CTLA-4 polymorphisms seems to be associated only with subgroups of patients [41] (Table 1).

\section{Coeliac disease}

Coeliac disease (CD) is a gluten-sensitive enteropathy characterized by small-bowel mucosal atrophy. CD differs from a "classical" autoimmune disorder in that a T-cellmediated immune response to immunodominant wheat gliadin (a component of gluten) peptides combined with the autoantigen tissue transglutaminase plays a crucial role in the disease. Ingestion of gluten-containing cereals induces immunologically mediated intestinal injury in genetically susceptible individuals [11, 42]. Although the HLA component of CD susceptibility is well characterized, genes other than HLA are probably involved in CD predisposition. In particular, a role for the so-called CELIAC3 region located on chromosome $2 \mathrm{q} 33$, which includes CTLA-4, has been envisaged [42]. However, recently an association with CTLA-4 polymorphisms has not been confirmed in Slovak and Slovene populations [34] (Table 1).

\section{Primary biliary cirrhosis}

Primary biliary cirrhosis (PBC) can be defined as a liverspecific autoimmune disease characterized by the destruction of intrahepatic bile ducts, frequently evolving into cirrhosis and hepatic failure [43]. The pathogenesis of $\mathrm{PBC}$ is not fully understood, but genetic factors seem to play a critical role [44]. Previous studies have shown that $\mathrm{T}$ cells abundantly infiltrate the hepatic tissue $[45,46]$, and the pyruvate dehydrogenase complex might be one of the target antigens [47]. The 49AG and CT60 polymorphisms of CTLA-4 have been studied in PBC, but the results observed are controversial [48]. In a Japanese population only one haplotype (CGGA) over five examined single nucleotide polymorphisms was significantly associated with susceptibility to PBC [48] (Table 1).

\section{Soluble form of CTLA-4}

A sCTLA-4, namely a functional molecule with specific CD80 and CD86 binding ability, generated by alterna- tively spliced mRNA has been described $[10,13,20$, 49-53]. The mRNA encoding sCTLA-4 consists of three exons: exon 1 encoding the leader peptide, exon 2 the ligand-binding domain, and exon 4 the cytoplasmic tail, but it lacks exon 3 encoding the transmembrane domain [10, 20, 53]. The spliced transcript produces a 23-kDa sCTLA-4 characterized by a cytoplasmic tail shorter than that of the full-length form of the CTLA-4 antigen. As sCTLA-4 lacks the cysteine residue at position 120, it is expressed as a monomer [53-55]. In addition, sCTLA-4 contains the MYPPPY motif located in the extracellular domain which is critical for B7 molecule binding [23]. Therefore it maintains the ability to bind CD80/CD86 and to participate in the B7/CTLA-4/CD28 signalling pathway of T-cell regulation [10, 20, 53].

Soluble CTLA-4 transcripts have been detected in lymph nodes, spleen, CD4 and CD8 subsets of T cells, B lymphocytes [10], and in monocytes [8, 56], but not in a wide variety of nonlymphoid tissues. A distribution analysis of the soluble and full-length CTLA-4 transcripts among the CD4 and CD8 subsets of T cells has demonstrated that CD4 cells express both transcripts at the same level, whereas CD8 cells appear to express nearly 2.5-fold more full-length product with respect to sCTLA-4 [10, 20, 53]. An analysis of the association between the sCTLA-4 mRNA level and exon $1+49$ A/G and CT60A/G CTLA-4 gene polymorphisms in healthy subjects also showed that the sCTLA-4 mRNA level in unstimulated CD4 T cells is higher for allele A at position +49 and the CT60 A variant [29].

Detectable levels of sCTLA-4 have been demonstrated in human serum by immunometric assays and western blot analysis $[10,11,13,20,49,51,53,55-60]$. Recently, however, on the basis of mass spectrometry and biochemical evaluation, the possibility that at least some of the B7 binding material isolated from serum by means of CTLA4 antibodies is not a product of the CTLA4 gene has been considered [61].

\section{SCTLA-4 and autoimmune diseases}

Abnormal expression of CTLA-4 may result in the development of autoimmunity in experimental systems and in the autoimmune phenotype of the CTLA-4-deficient mouse. In light of this information, the role of SCTLA-4 in activated cells due to its association with autoimmunity has been studied. Increased serum levels of sCTLA-4 have been reported in patients with several autoimmune diseases significantly more often than in healthy individuals [20, 33, 49-51, 60, 62]. Patients with GD [20, 33, 49], HT [20, 49], MG [50], systemic lupus erythematosus [55], systemic sclerosis (SSc) [54], CD [51], autoimmune 
pancreatitis (AIP) [62] and spondyloarthropathies and RA [60] have been investigated. The first studies on sCTLA-4 serum levels in autoimmune disease were performed 10 years ago [20] in 17 patients with GD and 3 patients with HT. Of the 20 patients, 11 had circulating levels of sCTLA-4 in the range $28-78 \mathrm{ng} / \mathrm{ml}$, whereas only 1 of the 30 apparently healthy volunteer controls had an sCTLA-4 level greater than $4 \mathrm{ng} / \mathrm{ml}$ [20].

In a more recent study, we found sCTLA- 4 in 59 out of 90 serum samples from patients with autoimmune thyroid diseases (both GD and autoimmune thyroiditis) with levels ranging from 0.1 to $50 \mathrm{ng} / \mathrm{ml}$. In contrast, 6 of 45 serum samples from healthy controls had detectable sCTLA-4 (from 0.1 to $36.1 \mathrm{ng} / \mathrm{ml}$ ) [49]. In addition, we observed that SCTLA-4 levels were not related to specific clinical manifestations, such as clinical thyroid status (hypo- or hyperthyroidism), circulating thyroid hormones, or other clinical features (ophthalmopathy). Thus, sCTLA-4 production does not seem to be affected by disease evolution over time [49]. However, a recent study has shown that increased sCTLA-4 serum levels correlate with the severity of Graves' ophthalmopathy [33]. The discrepancy in these finding may be related to the greater number of GD patients enrolled in the later study (93 vs. 31). In addition, significantly higher serum levels of SCTLA-4 were found in a group of 100 patients with SLE than in healthy controls $(21.6 \pm 12.3 \mathrm{ng} / \mathrm{ml}$ vs. $5.9 \pm 5.4 \mathrm{ng} / \mathrm{ml}, p<0.001)$ [53]. Elevated serum sCTLA-4 levels were found in 32 patients with diffuse cutaneous SSc compared with healthy subjects $(p<0.001)$, while mean serum sCTLA-4 levels in 27 patients with limited cutaneous SSc did not differ from those in control subjects [54].

In addition, sCTLA-4 seems to correlate with disease severity and activity of SSc [54]. Patients with MG also show increased serum levels of sCTLA-4 [50]. The median sCTLA-4 level in a group of 96 patients with MG was $6.8 \mathrm{ng} / \mathrm{ml}$ (range $0-1,200 \mathrm{ng} / \mathrm{ml}$ ), while in the control group it was $3.0 \mathrm{ng} / \mathrm{ml}$ (range $0-600 \mathrm{ng} / \mathrm{ml} ; p<0.001$ ) [50]. The serum levels of sCTLA-4 have been found to be positively correlated with the serum concentration of antibodies against the acetylcholine receptor $(r=0.396$, $p<0.01$ ) [50]. Among MG patients classified according to thymic histopathology those with thymoma were found to have higher levels of sCTLA-4 than the others [50]. No difference in serum sCTLA-4 level was found between patients with and without immunosuppressive treatment $[50,63]$. In addition, there was no correlation between CTLA-4 gene polymorphisms in the promoter region at position -319 [63] and in the 3'-UTR of exon 4 at position 642 [50] and the levels of sCTLA-4 in patients with these autoimmune diseases.

More recently, we found an increased in SCTLA-4 levels in the serum of patients with untreated CD (in 54 out of $75 \mathrm{CD}$ patients; range $0.1-96.4 \mathrm{ng} / \mathrm{ml}$ ), and analysed its possible immunoregulatory function [51]. A comparison of these results with those obtained in 85 patients with $\mathrm{CD}$ in remission on a gluten-free diet showed that sCTLA-4 concentrations are related to gluten intake. A correlation between autoantibodies to tissue transglutaminase or the degree of mucosal damage and sCTLA-4 concentrations $h$ also been found [51]. In addition, we have observed that serum sCTLA-4 is able to downregulate the proliferative ability of $\mathrm{T}$ lymphocytes in vitro [51].

A possible genetic association between CTLA-4 polymorphism and AIP has been shown $[62,64]$. In addition, a recent study has shown that serum SCTLA-4 levels are increased in AIP [62]. The analysis was performed in a group of 52 patients and 32 controls. Serum sCTLA-4 levels were significantly higher in patients with AIP (average $8.9 \mathrm{ng} / \mathrm{ml}$ ) than in healthy subjects (2.9 $\mathrm{ng} / \mathrm{ml}$ ). In addition, the $+6230 \mathrm{G} / \mathrm{A}$ polymorphism was increased in AIP, although it did not influence sCTLA4 levels in AIP patients.

In recent years, interest in sCTLA-4 has extended from the original study of autoimmunity towards a wider field of analysis. Studies in patients with allergic asthma [12] and allergy to Hymenoptera venom [13] are examples. In addition, very recent studies suggest the possibility of using sCTLA-4 as a biomarker of inflammation [14] and indicate that some polymorphisms of CTLA-4 are important factors associated with risk of or protection from some infectious diseases [39].

\section{Does SCTLA-4 regulate lymphocyte functions?}

Cellular activation appears to regulate the relative level of each CTLA-4 transcript. sCTLA-4 mRNA expression is inhibited after $24-48 \mathrm{~h}$ of activation with concanavalin A plus phytohaemagglutinin [20]. After 72-120 h of activation the sCTLA-4 transcript increases, but it does not exceed about two-thirds of total mRNA CTLA-4 [20]. Similar results were obtained upon activation of human peripheral blood mononuclear cells with anti-CD3 plus anti-CD28 [20]. In addition, short-term Tcell stimulation with phorbol 12-myristate plus ionomycin for $6 \mathrm{~h}$ or anti-CD3 plus anti-CD28 monoclonal antibody has been shown to lead to inhibition of mRNA sCTLA-4 expression [20]. It was also observed that interferon beta-1a (IFN- $\beta 1$ a) enhances the expression of sCTLA-4 in human mononuclear cells from healthy subjects [65]. Analysis of unstimulated mononuclear cells incubated in complete medium with and without IFN$\beta 1 \mathrm{a}$ for $72 \mathrm{~h}$ did not show any differences in cDNA fulllength CTLA-4 band intensity, whereas the amount of 
sCTLA-4 transcript was higher after IFN- $\beta 1$ a treatment. This result shows a selective induction of $\mathrm{sCTLA}-4$ by IFN- $\beta 1 \mathrm{a}$ in human cells which might exert immunomodulatory effects [65].

Several studies have shown that serum sCTLA-4, as well as the recombinant form, is able to inhibit the mixed leucocyte reaction in a dose-dependent manner (up to complete inhibition at high concentrations) $[10,11,13$, $49,51]$. It has been shown $[66,67]$ that recombinant sCTLA-4 protein (CTLA4-Ig) induces different types of APCs, including dendritic cells, to catabolize tryptophan by indoleamine-2,3-dioxygenase. This process is important in inhibiting T-cell proliferation [68].

The finding that levels of sCTLA-4 are directly related to the levels of proinflammatory cytokines [14] supports the hypothesis of the immunoregulatory capability of SCTLA-4 in vivo. Thus, sCTLA-4 might be one of the factors causing the appearance of dysregulated $\mathrm{T}$ lymphocytes in the elderly.

\section{What does raised sCTLA4 really mean?}

Since our 2008 update 11 new articles on the genetic polymorphisms of CTLA-4, and three on the presence of SCTLA-4 in the serum of autoimmune patients, have been published [11], underlining the high level of interest in these topics. The critical point emerging from the literature is that the relationship between CTLA-4 polymorphisms and the ability to produce the soluble form is not fully clarified. In addition, such a relationship seems in some points contradictory. Indeed, it is difficult to explain why autoimmune disease susceptibility genotypes $(+49 \mathrm{G} / \mathrm{G}$ and $\mathrm{CT} 60 \mathrm{G} / \mathrm{G})$ are associated with lower levels of sCTLA-4 transcripts [10, 11, 35, 61, 62, 69-74]. It may be hypothesized that abnormal translation of both CTLA-4 transcripts (sCTLA-4 and full-length CTLA-4) and/or abnormal intracellular trafficking and release of sCTLA-4 may occur in patients with autoimmune diseases with high levels of sCTLA-4. Moreover, sCTLA-4 production seems to be correlated with a complex genetic control involving not only the CTLA-4 gene, but other related polymorphic genes, such as ICOS [75]. As a last point, as mentioned above, one recent report [61] questioned whether the soluble molecules recognized by CTLA-4 monoclonal antibodies and able to bind B7 antigens (isolated from the serum of MG patients) are definitely products of CTLA-4 transcripts.

Nevertheless, the increase in SCTLA-4 seems to be a quite general phenomenon potentially relevant for the pathogenesis of autoimmune diseases. In fact, sCTLA-4 may have important immunoregulatory functions. On the one hand, sCTLA-4 may bind CD80/CD86 natural lig- ands expressed on APC and thus interfere with CD80/CD86:CD28-mediated costimulation of the early T-cell responses (Fig. 1a). On the other hand, sCTLA-4 may also be capable of interfering with CD80/CD86:CTLA-4 interactions, thereby blocking the negative signal imparted via the membrane-bound form of CTLA-4 in the later phases of T-cell responses (Fig. 1b). Thus, such a regulatory role of this soluble molecule could also be exerted at the cytokine production level. In fact, it has been found that the production of IL-2, IFN- $\gamma$, and IL-13 is sharply reduced following crosslinking of the CTLA-4 inhibitory receptor; in contrast, the production of IL-10 and TGF- $\beta$ is significantly increased. The biological functions of these cytokines are known $[9,76]$. It follows that the out-

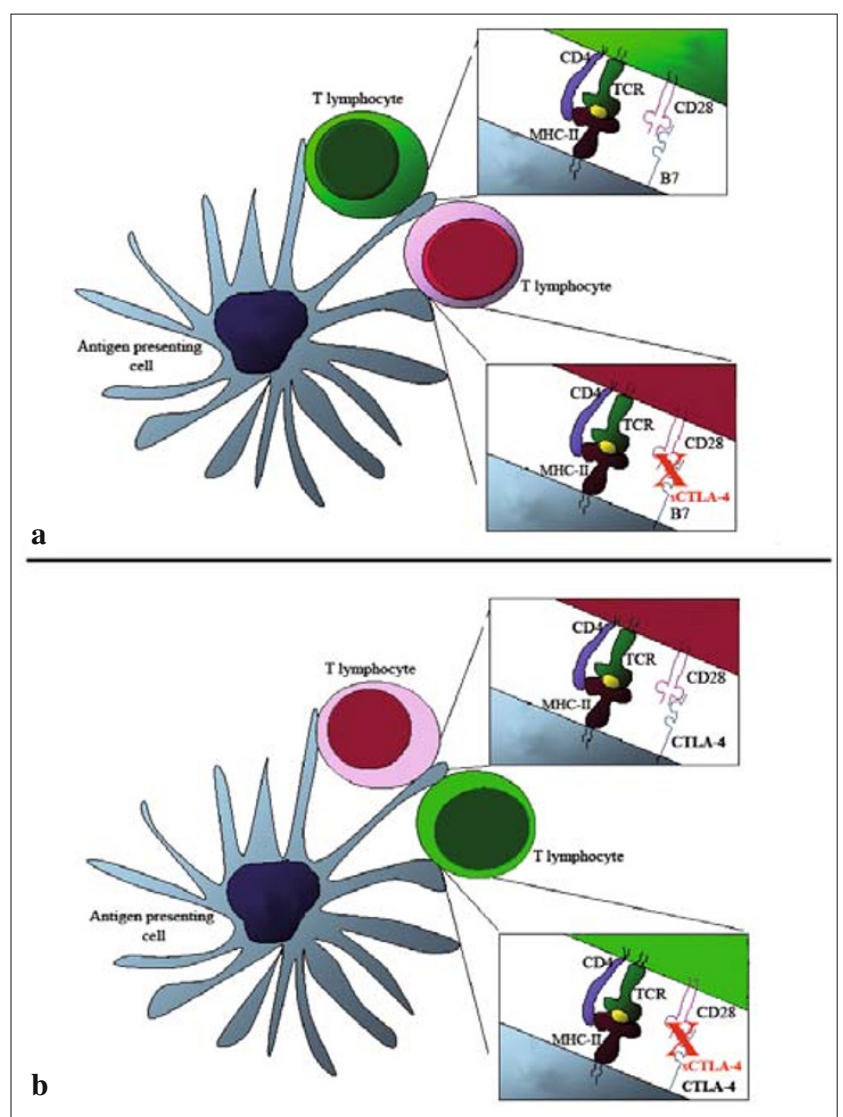

Fig. 1 T-cell activation and costimulatory signals: does sCTLA-4 interfere with T-cell functions? a T-cell activation requires two signals: the first is provided by antigen-TCR engagement and the second is mainly provided by the interaction of the costimulatory molecule, CD28, with its B7 ligands, on APCs. The presence of sCTLA-4 during the initial phase of T-lymphocyte activation could block the binding of B7 to CD28, resulting in inhibition of T cells. b The CTLA-4 membrane receptor is a costimulatory molecule able to bind the B7 ligands and, in contrast to CD28, provides a negative signal for T-cell activation. CTLA-4 is expressed during the late phase of T lymphocyte activation. In this context, sCTLA-4 could prevent the interaction between the membrane-bound CTLA- 4 and B7, resulting in a reduced negative signal (i.e. ongoing T-lymphocyte activation). Green T lymphocytes activated, red T lymphocytes inhibited 
come of CD80/CD86 engagement by sCTLA-4 could result in control of cell-mediated autoimmunity.

It is not possible, in our opinion, to claim that sCTLA-4 is a clinically useful biomarker for the management of autoimmune disease on the basis of the data available to date. However some points deserve attention and open a possible perspective. For example, in our study mentioned above [51] follow-up of serum sCTLA4 in CD demonstrated a significant SCTLA-4 reduction following exogenous gluten withdrawal. In another disease, namely GD [49], in which the presence of triggering autoantigen(s) is long-lasting, we have observed high sCTLA-4 levels even after radioiodine treatment. The time-course of serum SCTLA-4 reduction in CD in comparison to tissue transglutaminase autoantibodies requires specific investigation to ascertain its possible clinical added value. Even more importantly, we have shown that SCTLA-4 in CD closely correlates with gut histology in untreated disease. This is of potential interest due to the clinical need for serological markers correlating with the degree of villous atrophy [77, 78].

Conflict of interest The authors declare that they have no conflict of interest relating to the publication of this manuscript.

\section{References}

1. Lenschow DJ, Walunas TL, Blueston JA (1996) CD28/B7 system of T cell costimulation. Annu Rev Immunol 14:233-258

2. Bocko D, Kosmaczewska A, Ciszak L et al (2002) CD28 costimulatory molecule - expression, structure and function. Arch Immunol Ther Exp 50:169-177

3. Shapiro VS, Truitt KE, Imboden JB et al (1997) CD28 mediates transcriptional upregulation of the interleukin-2 (IL-2) promoter through a composite element containing the CD28RE and NF-IL2B AP-1 sites. Mol Cell Biol 17:4051-4058

4. Walunas TL, Lenschow DJ, Bakker CY et al (1994) CTLA-4 can function as a negative regulator of $\mathrm{T}$ cell activation. Immunity $1: 405-413$

5. Krummel MF, Allison JP (1995) CD28 and CTLA-4 have opposing effects on the response of T cells to stimulation. J Exp Med 182:459-465

6. Saverino D, Tenca C, Zarcone D et al (1999) CTLA-4 (CD152) inhibits the specific lysis mediated by human cytolytic T lymphocytes in a clonally distributed fashion. J Immunol 162:651-658

7. Merlo A, Tenca C, Fais F et al (2005) Inhibitory receptors CD85j, LAIR-1, and CD152 down-regulate immunoglobulin and cytokine production by human B lymphocytes. Clin Diagn Lab Immunol12:705-712

8. Laurent S, Carrega P, Saverino D et al CTLA-4 is expressed by human monocyte-derived dendritic cells and regulates their functions. Hum Immunol. DOI: http://dx.doi.org/10.1016/j.humimm.2010.07.007

9. Saverino D, Merlo A, Bruno S et al (2002) Dual effect of CD85/leukocyte Ig-like receptor-1/Ig-like transcript 2 and CD152 (CTLA-4) on cytokine production by antigen-stimulated human T cells. J Immunol 168:207-215

10. Oaks MK, Hallett KM, Penwell RT et al (2000) A native soluble form of CTLA-4. Cell Immunol 201:144-153
11. Simone R, Saverino D (2009) The soluble CTLA-4 receptor and its emerging role in autoimmune diseases. Curr Immunol Rev 5:54-68

12. Wong CK, Lun SWM, Ko FW et al (2005) Increased expression of plasma and cell surface co-stimulatory molecules CTLA-4, CD28 and CD86 in adult patients with allergic asthma. Clin Exp Immunol 141:122-129

13. Saverino D, Riccio AM, Rogkakou A et al (2009) Serum CTLA4 in Hymenoptera venom allergy end its modulation by specific immunotherapy. J Allergy Clin Immunol 123:258-260

14. Sakthivel P, Wermeling F, Elmgren A et al (2010) Circulating soluble CTLA-4 is related to inflammatory markers in the 70 year old population. Scand J Clin Lab Invest 70:237-243

15. Tunbridge WM, Evered DC, Hall R et al (1997) The spectrum of thyroid disease in a community: the Whickham survey. Clin Endocrinol 7:481-493

16. Ueda H, Howson JM, Esposito L et al (2003) Association of the T-cell regulatory gene CTLA4 with susceptibility to autoimmune disease. Nature 423:506-511

17. Awata T, Kurihara S, Iitaka M et al (1998) Association of CTLA4 gene A-G polymorphism (IDDM12 locus) with acute-onset and insulin-depleted IDDM as well as autoimmune thyroid disease (Graves' disease and Hashimoto's thyroiditis) in the Japanese population. Diabetes 47:128-129

18. Kouki T, Sawai Y, Gardine CA et al (2000) CTLA-4 gene polymorphism at position 49 in exon 1 reduces the inhibitory function of CTLA-4 and contributes to the pathogenesis of Graves' disease. J Immunol 165:6606-6611

19. Mochizuki M, Amemiya S, Kobayashi K et al (2003) Association of the CTLA-4 gene $49 \mathrm{~A} / \mathrm{G}$ polymorphism with type 1 diabetes and autoimmune thyroid disease in Japanese children. Diabetes Care 26:843-847

20. Oaks MK, Hallett KM (2000) A soluble form of CTLA-4 in patients with autoimmune thyroid disease. $\mathrm{J}$ Immunol 164:5015-5018

21. Lafage-Pochitaloff M, Costello R, Couez D et al (1990) Human CD28 and CTLA-4 Ig superfamily genes are located on chromosome 2 at bands q33-q34. Immunogenetics 31:198-201

22. Harper K, Balzano C, Rouvier E et al (1991) CTLA-4 and CD28 activated lymphocyte molecules are closely related in both mouse and human as to sequence, message expression, gene structure, and chromosomal localization. J Immunol 147:1037-1044

23. Linsley PS, Greene JL, Brady WH et al (1994) Human B.7-1 (CD80) and B.7-2 (CD86) bind with similar avidities but distinct kinetics to CD28 and CTLA-4 receptors. Immunity 1:793-801

24. Nisticò L, Buzzetti R, Pritchard LE et al (1996) The CTLA-4 gene region of chromosome $2 \mathrm{q} 33$ is linked to, and associated with, type 1 diabetes. Hum Mol Genet 5:1075-1080

25. Deichmann K, Heinzmann A, Brüggenolte et al (1996) An Mse I RFLP in the human CTLA4 promotor. Biochem Biophys Res Commun 225:817-818

26. Davies TF (1996) The pathogenesis of Graves' disease. In: Braverman LE, Utiger RD (eds) The thyroid, 7th edn. LippincottRaven, Philadelphia, pp 525-536

27. Tomer Y, Huber A (2009) The etiology of autoimmune thyroid disease: a story of genes and environment. J Autoimmun 32:231-239

28. Weetman AP, McGregor AM (1994) Autoimmune thyroid disease: further developments in our understanding. Endocr Rev 15:788-830

29. Yanagawa T, Hidaka Y, Guimaraes V et al (1995) CTLA-4 gene polymorphism associated with Graves' disease in a Caucasian population. J Clin Endocrinol Metab 80:41-45

30. Zhao SX, Pan CM, Cao HM et al (2010) Association of the CTLA4 gene with Graves' disease in the Chinese Han population. PLoS One 5:e9821

31. Gu LQ, Zhu W, Zhao SX et al (2010) Clinical associations of the genetic variants of CTLA-4, Tg, TSHR, PTPN22, PTPN12 and 
FCRL3 in patients with Graves' disease. Clin Endocrinol 72:248-255

32. Yin X, Latif R, Bahn R et al (2008) Influence of the TSH receptor gene on susceptibility to Graves' disease and Graves' ophthalmopathy. Thyroid 18:1201-1206

33. Daroszewski J, Pawlak E, Karabon L et al (2009) Soluble CTLA4 receptor an immunological marker of Graves' disease and severity of ophthalmopathy is associated with CTLA-4 Jo31 and CT60 gene polymorphisms. Eur J Endocrinol 161:787-793

34. Dallos T, Avbelj M, Barák L et al (2008) CTLA-4 gene polymorphisms predispose to autoimmune endocrinopathies but not to celiac disease. Neuro Endocrinol Lett 9:334-340

35. Douroudis K, Prans E, Kisand K et al (2009) Cytotoxic Tlymphocyte antigen 4 gene polymorphisms are associated with latent autoimmune diabetes in adults. Clin Chim Acta 403:226-228

36. Saleh HM, Rohowsky N, Leski M (2008) The CTLA4 -819 C/T and $+49 \mathrm{~A} / \mathrm{G}$ dimorphisms are associated with Type 1 diabetes in Egyptian children. Indian J Hum Genet 14:92-98

37. Kristiansen OP, Larsen ZM, Pociot F (2000) CTLA-4 in autoimmune diseases - a general susceptibility gene to autoimmunity? Genes Immun 1:170-184

38. Fritze D, Herrman C, Naeim F et al (1974) HL-A antigens in myasthenia gravis. Lancet 1:240-242

39. Fernández-Mestre M, Sánchez K, Balbás O et al (2009) Influence of CTLA-4 gene polymorphism in autoimmune and infectious diseases. Hum Immunol 70:532-535

40. Wray BN, Stankovich J, Whittock L et al (2008) CTLA-4 and multiple sclerosis: the A49G single nucleotide polymorphism shows no association with multiple sclerosis in a Southern Australian population. J Neuroimmunol 196:139-142

41. Muñoz-Valle JF, Valle Y, Padilla-Gutiérrez JR et al (2010) The $+49 \mathrm{~A}>\mathrm{G}$ CTLA-4 polymorphism is associated with rheumatoid arthritis in Mexican population. Clin Chim Acta 411:725-728

42. Holopainen P, Naluai AT, Moodie S et al; Members of the European Genetics Cluster on Coeliac Disease (2004) Candidate gene region $2 \mathrm{q} 33$ in European families with coeliac disease. Tissue Antigens 63:212-222

43. Talwalkar JA, Lindor KD (2003) Primary biliary cirrhosis. Lancet 362:53-61

44. Gershwin ME, Mackay IR (2008) The causes of primary biliary cirrhosis: convenient and inconvenient truths. Hepatology 47:737-745

45. Invernizzi P, Selmi C, Poli F et al (2008) Human leukocyte antigen polymorphisms in Italian primary biliary cirrhosis: a multicenter study of 664 patients and 1992 healthy controls. Hepatology 48:1906-1912

46. Donaldson PT, Baragiotta A, Heneghan MA et al (2006) HLA class II alleles, genotypes, haplotypes, and amino acids in primary biliary cirrhosis: a large-scale study. Hepatology 44:667-674

47. Shimoda S, Nakamura M, Ishibashi H et al (1995) HLA DRB4 0101-restricted immunodominant $\mathrm{T}$ cell autoepitope of pyruvate dehydrogenase complex in primary biliary cirrhosis: evidence of molecular mimicry in human autoimmune diseases. J Exp Med 181:1835-1845

48. Joshita S, Umemura T, Yoshizawa K et al; Shinshu PBC Study Group (2010) Association analysis of cytotoxic T-lymphocyte antigen 4 gene polymorphisms with primary biliary cirrhosis in Japanese patients. J Hepatol 53:537-541

49. Saverino D, Brizzolara R, Simone R et al (2007) Soluble CTLA4 in autoimmune thyroid diseases: relationship with clinical status and possible role in the immune response dysregulation. Clin Immunol 123:190-198

50. Wang XB, Kakoulidou M, Giscombe R et al (2002) Abnormal expression of CTLA-4 by T cells from patients with myasthenia gravis: effect of an AT-rich gene sequence. J Neuroimmunol $130: 224-232$
51. Simone R, Brizzolara R, Chiappori A et al (2009) A functional soluble form of CTLA- 4 is present in the serum of celiac patients and correlates with mucosal injury and tTG antibody production. Int Immunol 21:1037-1045

52. Wang XB, Giscombe R, Yan Z et al (2002) Expression of CTLA4 by human monocytes. Scand J Immunol 55:53-60

53. Liu MF, Wang CR, Chen PC et al (2003) Increased of expression of soluble cytotoxic T-lymphocyte-associated antigen-4 molecule in patients with systemic lupus erythematosus. Scand J Immunol 57:568-572

54. Sato S, Fujimoto M, Hasegawa M et al (2004) Serum soluble CTLA-4 levels are increased in diffuse cutaneous systemic sclerosis. Rheumatology 43:1261-1266

55. Wong CK, Lit LCW, Tam LS et al (2005) Aberrant production of soluble costimulatory molecules CTLA-4, CD28, CD80 and CD86 in patients with systemic lupus erythematosus. Rheumatology 44:989-994

56. Bergholdt R, Taxvig C, Eising S et al (2005) BLB variants in type 1 diabetes and their genetic interaction with CTLA4. J Leukoc Biol 77:579-585

57. Brunet JF, Denizot F, Luciani MF et al (1987) A new member of the immunoglobulin superfamily - CTLA-4. Nature 328:267-270

58. Dariavach P, Mattei MG, Golstein P et al (1988) Human Ig superfamily CTLA-4 gene: chromosomal localization and identity of protein sequence between murine and human cytoplasmic domains. Eur J Immunol 18:1901-1905

59. Ligers A, Xu C, Saarinen S et al (1999) The CTLA-4 gene is associated with multiple sclerosis. J Neuroimmunol 97:182-190

60. Toussirot E, Saas P, Deschamps M et al (2009) Increased production of soluble CTLA-4 in patients with spondylarthropathies correlates with disease activity. Arthritis Res Ther 11:R101

61. Tector M, Khatri BO, Kozinski K et al (2009) Biochemical analysis of CTLA-4 immunoreactive material from human blood. BMC Immunol 10:51-60

62. Umemura T, Ota M, Hamano $\mathrm{H}$ et al (2008) Association of autoimmune pancreatitis with cytotoxic T-lymphocyte antigen 4 gene polymorphisms in Japanese patients. Am J Gastroenterol 103:588-594

63. Lowe RM, Graham J, Sund G et al (2000) The length of the CTLA-4 microsatellite (AT)N-repeat affects the risk for type 1 diabetes. Autoimmunity 32:173-180

64. Chang M-C, Chang Y-T, Tien Y-W et al (2007) T-cell regulatory gene CTLA-4 polymorphism/haplotype association with autoimmune pancreatitis. Clin Chemi 53:1700-1705

65. Grohmann U, Orabona C, Fallarino F et al (2002) CTLA-4-Ig regulates catabolism in vivo. Nat Immunol 3:1097-1101

66. Mellor AL, Munn DH (1999) Tryptophan catabolism and T-cell tolerance: immunosuppression by starvation? Immunol Today 20:469-473

67. Kawa S, Ota M, Yoshizawa K et al (2002) HLA DRB10405DQB10401 haplotype is associated with autoimmune pancreatitis in the Japanese population. Gastroenterology 122:1264-1269

68. Long EO (1999) Regulation of immune responses through inhibitory receptors. Annu Rev Immunol 17:875-904

69. Andreevski TV, Sudomoina MA, Gusev EI et al (2002) Polymorphism A/G in position +49 of CTLA4 exon 1 in multiple sclerosis in Russians. Mol Biol 36:643-648

70. Djilali-Saiah I, Schmitz J, Harfouch-Hammoud E et al (1998) CTLA-4 gene polymorphism is associated with predisposition to celiac disease. Gut 43:187-189

71. Orozco G, Torres B, Nunez-Roldan A et al (2004) Cytotoxic Tlymphocyte antigen-4-CT60 polymorphism in rheumatoid arthritis. Tissue Antigens 64:667-670

72. Vaidya B, Pearce S (2004) The emerging role of the CTLA-4 gene in autoimmune endocrinopathies. Eur $\mathrm{J}$ Endocrinol 150:619-626 
73. Giorelli M, Livera P, Defazio G et al (2001) IFN-beta1a modulates the expression of CTLA-4 and CD28 splice variants in human mononuclear cells: induction of soluble isoforms. J Interferon Cytokine Res 21:809-812

74. Finger EB, Bluestone JA (2002) When ligand becomes receptor tolerance via B7 signaling on DCs. Nat Immunol 3:1056-1057

75. Kaartinen T, Lappalainen J, Haimila K et al (2007) Genetic variation in ICOS regulates mRNA levels of ICOS and splicing isoforms of CTLA4. Mol Immunol 447:1644-1651
76. Swain SL, Huston G, Tonkonogy S et al (1991) Transforming growth factor-beta and IL-4 cause helper T cell precursors to develop into distinct effector helper cells that differ in lymphokine secretion pattern and cell surface phenotype. J Immunol 147:2991-3000

77. Catassi C, Fasano A (2010) Celiac disease diagnosis: simple rules are better than complicated algorithms. Am J Med 123:691-693

78. Sugai E, Moreno ML, Hwang HJ et al (2010) Celiac disease serology in patients with different pretest probabilities: is biopsy avoidable? World J Gastroenterol 16:3144-315 